and prisms to right and left, to form (or to reproduce) the lateral images, while the third part, not deflected, forms (or reproduces) the middle image. The lateral parts of the divided beam traverse a longer path than that of the middle part, and this difference of path must be compensated in order to bring all of the images into focus. The compensation can be effected by the interposition of lenses or of a number of plane-parallel glasses, but the lenses alter the relative dimensions of the images and the bundles of glass absorb much light and greatly increase the weight of the apparatus.

A great many three color processes have been patented, but few have given good results. The only one that has been exploited successfully in Europe is:

\section{exp oAumont cHronochrome PROCEss.}

The Gaumont film is of the usual width and contains the three monochromatic pictures in regular recurrence, but each triplet is projected simultaneously. With pictures of the usual dimensions, 18 by 24 millimeters ( $3 / 4$ inch by 1 inch) it would be necessary to advance the film 54 millimeters, or more than 2 inches at each step. In order to lessen the danger of tearing and also to diminish the cost of the film, Gaumont reduces the height of the picture by one third, withou altering the width, so that the dimensions are 12 by 24 millimeters ( $1 / 2$ inch by 1 inch: Fig. 1, No. 4).

The pictures are projected by three superposed lenses $(A, B, C$, Fig. 2), the centers of which are separated by intervals equal to the height of a picture, but the lenses are segments of lenses of much greater diameter than this, so that they transmit abundant light.

The middle lense $B$ is fixed; the other lenses $A$ and $C$ can be turned both vertically and horizontally. This rotation is required in order to superpose the images exactly on the screen. The regulation is a delicate operation and the operator is too far from the screen to observe the effect minutely. Therefore, he is aided by an observer placed near the screen who gives him needed warnings by telephone.

The three pictures are illuminated by a single electric arc. Three arcs would give more brilliant projections, but their fluctuations would injuriously affect the coloring. A very intense arc is employed in conjunction with a metallized screen, which, instead of diffusing the light in all directions, confines it chiefly to a small angular field. This method of projection is suitable only for small halls.

The reproduction of natural colors is perfect. This is strikingly shown in motion pictures of gorgeous tropical butterflies and flowers, mounted on rotating pedes- tals. The movement gives an impression of relief as complete as that produced by the stereoscope, and the illusion of reality is intensified by the play of color especially in the wings of butterflies, the colors of which are due to interference and change with the direction of the illumination.

\section{TWO-COLOR PROCESSES. KINEMACOLOR.}

In the Urban-Smith kinemacolor process the component colors are reduced to two: red and green. $\mathrm{Th}$ camera and the projecting lantern are similar to those used in the three color process with successive images, except that the rotating disk has only two transparen sectors, red and green, separated by two opaque sectors (Fig. 3). The film moves at the rate of 32 picture per second, twice the usual speed, and its length (Fig. 1 , No. 3) is twice that of a black-and-white film of the same subject

The absence of the third fundamental color has bee partly compensated by substituting for the opaque sectors of the rotating disk blue-violet sectors which are not sufficiently transparent to reveal the movement of the film that takes place when behind them (Fig. 4) By this device the predominant yellow tone of th screen picture is corrected. The blue color is spread uniformly over the picture, instead of being localize in the blue parts, but our eye is very tolerant and it synthesis of color is purely subjective. In the reproduction of natural colors, however, kinemacolor is far inferior to the Gaumont process.

\section{THE AUTOCHROME PROCESS.}

The three films and color screens of the three color process can be replaced by a single film composed of violet, green, and orange elements (Fig. 1, No. 5). If the colored elements are very small and uniformly distributed the film will appear colorless. If such a film is coated with silver bromide emulsion and exposed i a camera, the result will be a photograph in colors, in which a deposit of silver covers all of the little colore elements that do not correspond with the natural hues of the subject.

The production of color photographs of this sort has been the object of many researches. The most successful method yet invented is that of MM. A. and L. Lumière, whose autochrome plate is prepared with grain of starch, colored violet, green, and orange, thoroughly mixed and spread in a thin layer between the sensitive emulsion and its support.

This process furnishes beautiful lantern slides, but its application to motion pictures is attended with difti- culties that have not yet been overcome. The colored starch grains, and the yellow glass required for correcting the tone of the picture, absorb so much light that, even with an exceedingly sensitive emulsion, the exposure must be at least 60 times longer than in mono chrome photography, so that the production of motion pictures is impossible, except in special cases.

If this and other less formidable obstacles can be surmounted the autochrome process will furnish films lighter, less bulky and possibly cheaper than those of the three color process with successive images. It will not be necessary to reduce the height of the pictures or to employ a special lantern for projection.

\section{Producing Steel Direct from the Ore}

MANY investigators have worked on methods of producing steel direct from the iron ore without resorting to the present preliminary process of reducing the ore in a blast furnace, and it is obvious that if a commercially practical process of this kind can be perfected a very great saving in time and expense will result, together with a considerable saving in ore. As a result of many experiments, it would appear that the electric furnace would give the best results as, for one thing, the uncertainties resulting from impurities introduced by fuel would be entirely avoided. In a recent issue of the Journal of the Iron and Steel Institute the results of experiments made by E. Humbert and A. Hethey are discussed. Experiments were made in a normal Heroult electric furnace of 6 tons' capacity, working with singlephase current. Three series of tests were made, namely: (1) Direct reduction of siliceous Swedish iron ore (2) Direct reduction of Swedish and a siliceous Swedish iron ore, with 30 per cent of scrap mixed with the charge. (3) Direct reduction of Brazilian iron ore. It was found that good steel could be obtained without the carbon being above 0.4 per cent at any time. The steel forged very well and welded easily. The consumption of electrodes was at the rate of 32 kilogrammes per ton of steel. The wear of, the lining was approximately the same as when melting scrap, but there was a good deal of ebullition owing to the liberation of large volumes of oxides of carbon. The outstanding quality: of , steel by this process is its toughness. The authors claim that the steel is. more free from harmful gases, such as nitrogen, by this process; and that the direct :method has the advantages of simplicity, ability to use refractory and richer ores, freedom from impurities, cheapness, and efficient control of the quality of the steel.

\title{
Circumventing Niagara Falls
}

\section{A New Welland Canal Necessitated by Increasing Traffic}

\section{By Bernard Farrows}

IT was a spectacular feat to drive a canal across the Isthmus of Panama. The world has looked on in open mouthed astonishment as skillful engineers and toiling laborers have removed mountains, flooded valleys and dug enormous channels so that the commerce of the nations might flow from ocean to ocean.

In a sense it will be a scarcely less picturesque achievement to circumvent that great natural obstacle to the navigation of the Great Lakes of America, the Falls of Niagara, and by providing a ship canal around it, to enable the largest vessels now afloat in these waters to pass with facility from end to end of the long chain of lakes.

The latter task has been undertaken. Indeed, it is now well under way, and almost a year's progress has been made on the preliminary construction work. Awed doubtless by the superior accomplishments of the engineers at Panama, the men who are engaged in the enterprise at Niagara are saying very little about their undertaking, which is perhaps the reason why no one has heard very much as yet about it.

While the Welland Ship Canal, as the waterway is to be called, is to all intents and purposes an entirely new scheme, it will yet supersede a smaller canal which has been.in.existence many years. The circumventing.of the Falls of Niagara is no novelty. It was attempted quite early in the history of lake navigation. As far back as 1829 two ships sailed through the partially completed channel from Lake Ontario to the uppe reaches of the Niagara River, and four years later a thorough connection was established between Lakes Ontario and Erie from Port Dalhousie on the former to Port Colborne on the latter.

Since the thirties of last century, the Welland Canal has been twice rebuilt in order to accommodate the slowly enlarging types of vessels in use on the Great Lakes. The present canal, completed in 1880, was re garded at the time as the last word in canal construction. Its locks, twenty-six in number, and of dimen- sions 270 by 45 feet, were able to hold the largest ship then plying on the upper lakes, while the 14-foot channel was ample for the needs of the days.

But the amazing progress which has been made o late years in marine architecture has produced a typ of lake freighter that far exceeds in length, tonnage, and draft the one-time generous measurements of the Welland Canal. The latter has been rendered entirely useless in the case of a large proportion of the shippin of the lakes, and once again the Niagara cataract's barrier has become an effective impediment. Compare with the traffic through the Soo canals, that through the Welland Canal is at present a mere bagatelle, whic means that a very large percentage of the commerce of the upper lakes now terminates above the Falls.

As the bulk of the trafic through the canal at pres ent is grain, and as few of the upper lake boats can pass, the Canadian government has recently built a Port Colborn, the Lake Erie entrance, an elevator of $2,000,000$ bushels cap

into smaller vessels.

These facts established the need for a third enlargement of the Welland Canal and were considered by the government of Canada as of sufficient weight to warrant a reconstruction on a very much larger scale. The old route was examined with a view to sizing up it suitability for enlargement. It was promptly condemned, except for the southern section from Allanbur to Lake Erie. This meant a new location for the north ern half of the canal and, after much prospecting, route lying to the eastward of the old route was decided upon. Plans were promptly prepared for the construction of the canal and about a year ago

As comparisons often present a more illuminating idea of a subject than plain statements of fact, the importance of the new project may perhaps be better gaged by comparing it with the Panama Canal. The Panama Canal has a length of fifty miles from ocean to ocean; the Welland measures twenty-five miles from lake to lake. The minimum width of the bottom of the channel in the case of the Panama Canal is 300 feet; in that of the Welland Canal it is 200 feet. The minimum depth of water throughout the Panama Canal is 41 feet; in the Welland Canal it is 25 feet, though all permanent structures are to be made so that at any time the channel can be dredged to a depth of 30 feet.

The Panama Canal consists of three sections, viz., the Gatun Lake, formed by the damming of the Chagres River, and the channels leading to it from the Atlantic and Pacific, respectively. The mean level of the lake is 85 feet above sea level and ships are raised to its level by means of six locks, three at either end of the lake. The locks measure 1,000 by 110 feet, with a minimum depth of water over the sills of $41 \frac{1 / 3}{3}$ feet, when the ake is at its normal level. Each has a lift of $281 / 3$ feet. The Welland Canal, on the other hand, cannot be divided into such well-defined sections. Its course is entirely upward from Lake Ontario to Lake Erie, or, in other words, it has no summit level equivalent to Gatun Lake whence ships must be locked down again. The rise is contained almost entirely within a few miles of Lake Ontario and amounts to 325 feet, the difference in level of the two lakes. This is overcome by means of seven locks, of which Nos. 4, 5, and 6 are double and arranged in flight. The uniform size of the locks is 800 by 80 feet, with 30 feet of water over the miter sills at xtreme low stages in the lakes.

There is a further interesting comparison which may be instituted. The larger of the lock gates in the case of the Panama Canal each measure 65 feet in width by. 82 feet in height and weigh 730 tons. These gates a re of the double-leaf variety, hung on either side of the end of the lock and mitering in the center when closed. In the case of the lock gates for the Welland Canal, a novelty is to be introduced. The latter will not be double-leaf gates, but will be all in one piece and will swing right across the ends of the locks into mortises. 
They will measure 83 feet in height and 88 feet in width and will weigh 1,100 tons. It is believed by the designe that the new type of gate will be less liable to accident and will prove superior in many respects to the oldstyle double-leaf gate. The Welland Canal gates will not stand squarely across the channel, but will slant into the opposite wall, the length of the gate bein 3 feet more than the width of the canal. The submerged portion of the gate will serve as a floatin chamber and will relieve the pivot upon which the gate is swung of much of its weight, although the pin is designed to carry the weight of the gate plus its weight filled with water.

Another point of interest in connection with the We land Canal locks relates to the source of supply of water for filling them. Hitherto it has been customary to draw the water from the channel above each lock and, when the dimensions were small, this was a satis-

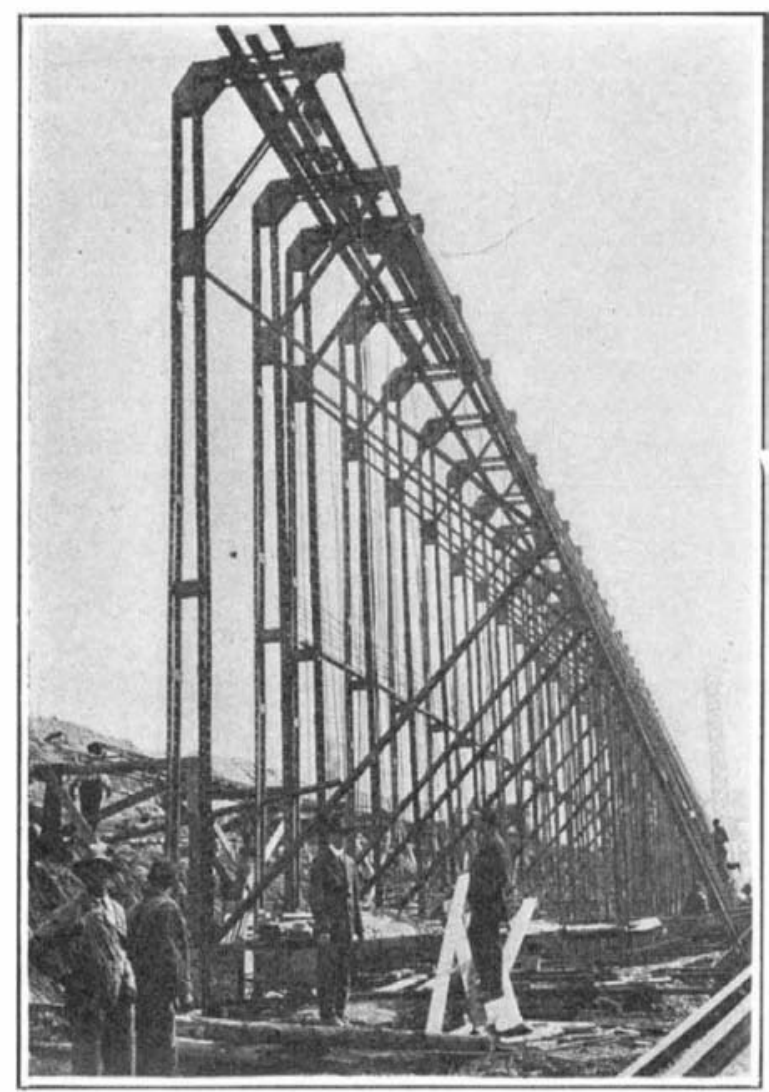

Steel core framework of retaining wall at the Lak Ontario entrance of the new Welland canal.

factory enough method. But with the huge basins of the new locks to fill each time a ship went through and with the rapid system of operation invented, a strong current would be set up which would interfere with navigation and tend to wear away the banks. Accordingly, above or beside each lock on the new ship canal, provision is being made for large reservoirs of water, from which the supply for filling is to be drawn. The water will consequently enter the locks through the side walls and not through the upper ends, completely obviating the disadvantages referred to.

The foregoing facts and figures will serve to show that the Welland Ship Canal, while by no means the gigantic project that the Panama Canal was, is still sufficiently near it both in size and in many engineering features to be classed as a notable undertaking. It is true that there are to be found at Niagara a few of the serious obstacles to progress which made the work of building the Panama Canal so long-drawn-out and diffi- cult. Conditions for carrying out the work are much better in the northern hemisphere than in the tropics. The contractors are near their base of supplies; labor is plentiful; the climate is healthy. Above all, there will be no discouraging Culebra Cut to try the patience of the engineers. The going will be comparatively easy and for many miles will consist simply of widening total excavation, as estimated by the chief engineer, will only amount to $46,000,000$ cubic yards, as compared with $220,000,000$ cubic yards at Panama.

A satisfactory beginning has been made, as already indicated, and from Lake Ontario to the summit of the Niagara escarpment, good progress is to be noted in the rork of excavation. The usual methods are in vogue. From the base of the escarpment to the shore of the lake the contractors have built a well-equipped standard-gage double-track railway, along which the material gouged out by the steam shovels is conveyed. For the present it is being used in building the piers that will form the capacious harbor of Port Weller. The lake shore at this point was unbroken and without any natural facilities for forming a harbor. It became neces. ural facilities for forming a harbor. It became neces-
sary therefore to build an artificial shelter for ships entering or leaving the canal, and, accordingly, two piers, 500 feet in width and a mile and half long, are being thrown out into the lake.

From the inner end of the harbor to the entrance of Lock No. 1, which will be located quite near the shore, retaining walls of unique construction are being built. These consist of triangular frameworks of steel, set in solid concrete and reinforced with numberless iron rods. The frames are encased in cement forming a long series of pockets, which in turn are filled in with sand and gravel. It has been' demonstrated that this style of wall is quite as effective as solid cement and of much more economical construction.

Naturally, the building of the ship canal is working great changes in the countryside. The section from the lake to the foot of the escarpment crosses what is known as the Garden of Ontario, a district famous for its production of peaches, grapes, and all kinds of small fruits. In its course the canal devastates many fine rchards and has caused the diversion of roads and a general cutting up of the landscape. At least two railways have had to be lifted to new rights of ways to make room for it and one small town has been cut in two by its deep excavations.

As originally estimated, 1918 was to have seen the completion of the work. Owing, however, to conditions imposed by the war which have compelled the Canadian government to cut down their expenditure on the canal, the time of construction will be spread over a longer period, and it may be 1920 or even later before big hips can use the new route from the upper to the lower

Meantime it is possible to consider the significance of the project and to estimate what its completion will mean to lake navigation. Eight hundred-foot locks and a 25-foot channel mean that not only can lake vessels of the largest tonnage use the canal, but that many ocean liners will be able to pass through to upper lake ports. While much of the traffic of the lakes will continue to terminate at or above Buffalo, there is no doubt that a considerably larger proportion of it than heretofore will descend to Lake Ontario through the new canal. Assuredly, conditions will be very much changed when the Niagara cataract is once more effectively circumvented. The bulk of the freight traftic to be handled on the new waterway will be grain, though there will be enormous quantities of coal and other bulk freight destined for upper lake ports. According to the liberal Canadian regulations, the canal will be free to al vessels using it It will be of great benefit the United States as well as to the Dominion of Canada.

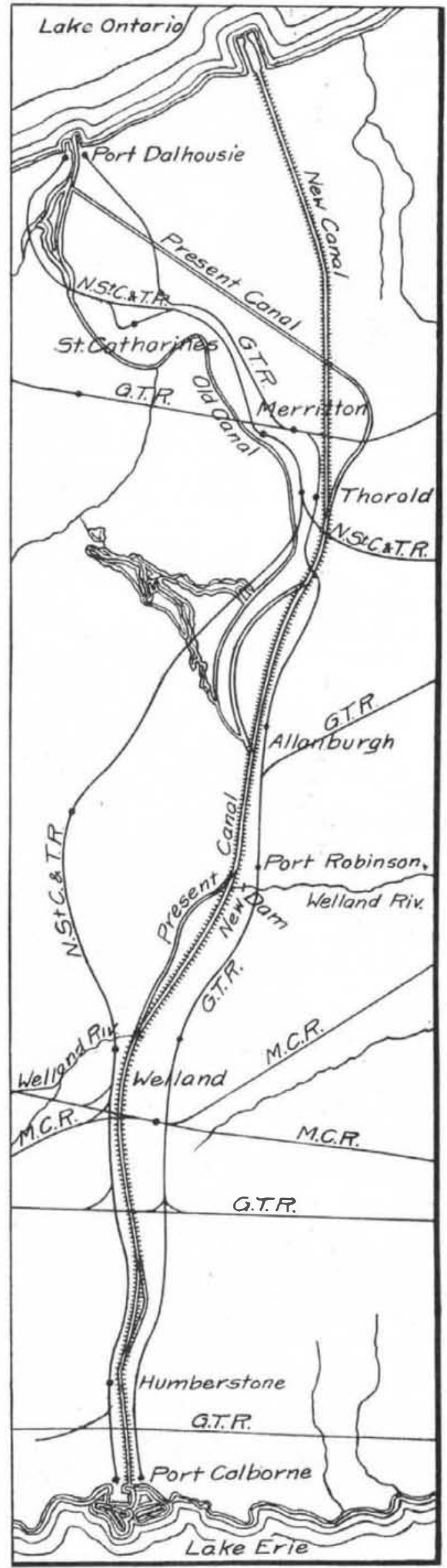

Old and new Welland canals between Lakes Erie and Ontario.

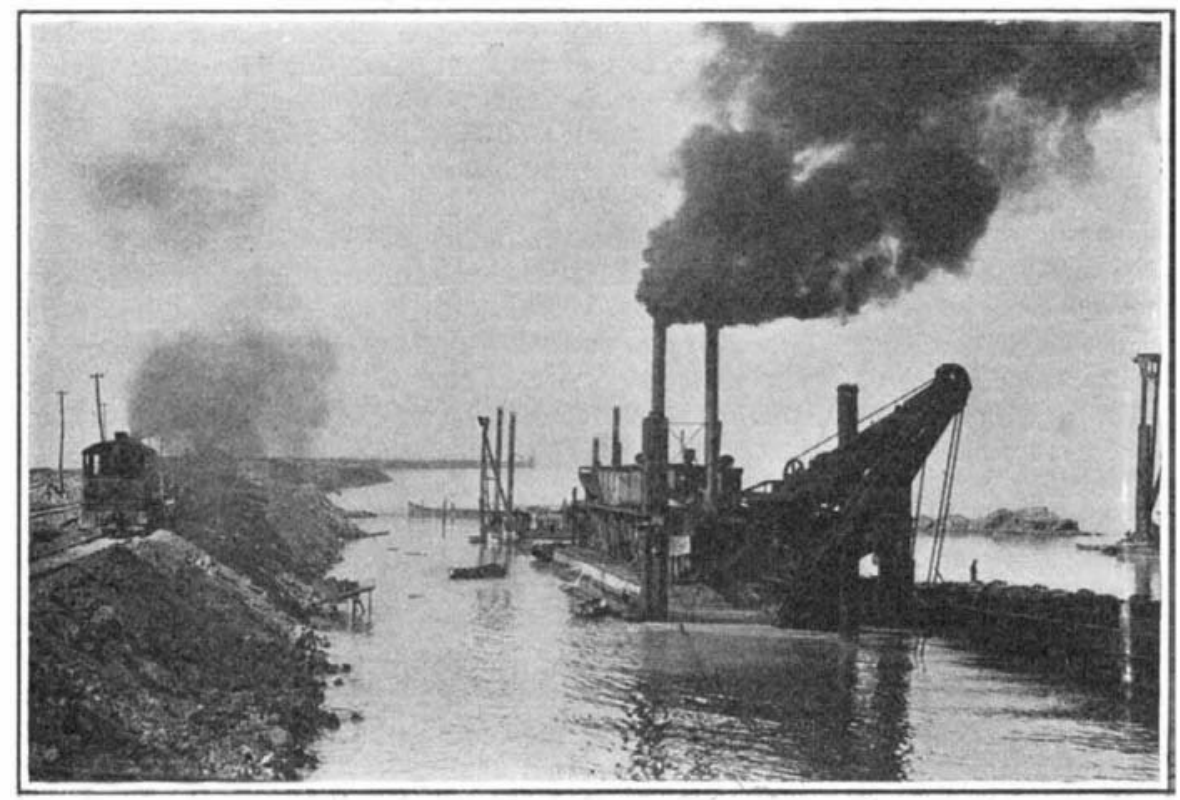

Fixcavating entrance harbor for the new Welland canal at Port Weller.

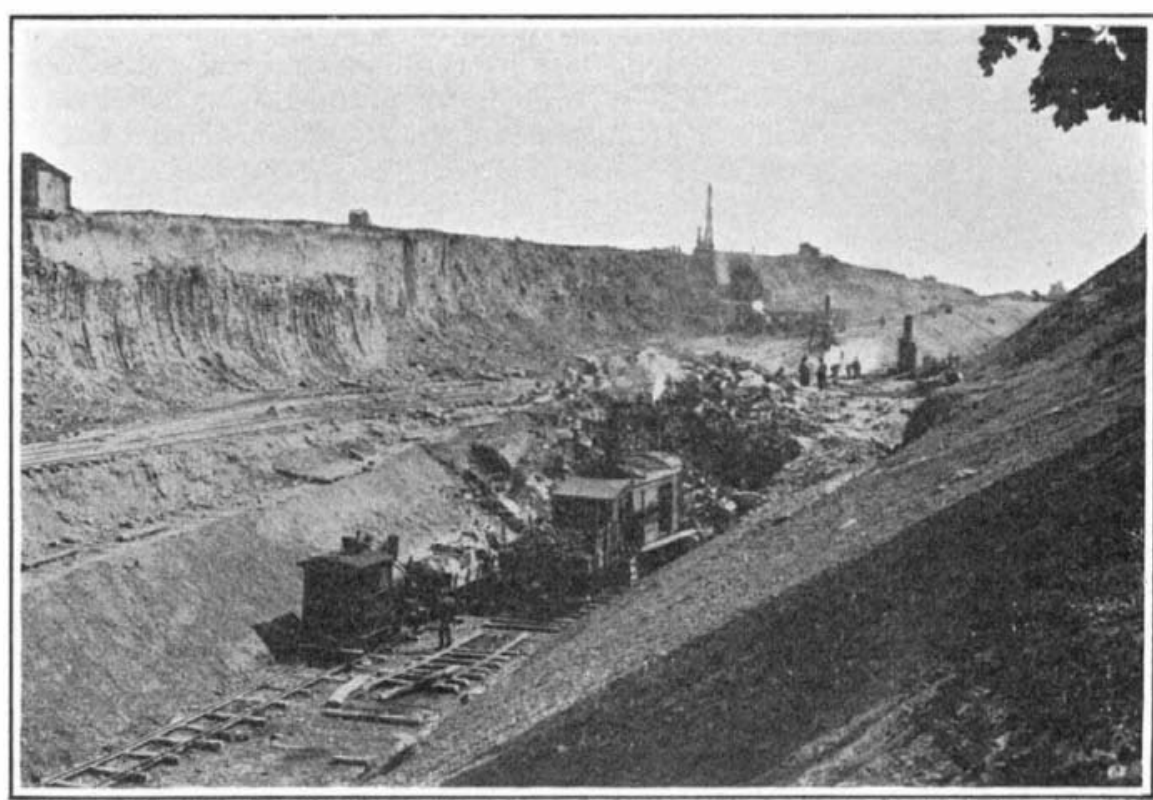

Deep cut on the new Welland canal at the top of the Niagara escarpment. 